
магистр техники и технологии, аспирант, Иркутский национальный исследовательский технический университет, e-mail: huanco.k7a@gmail.com

Чан Зюй Хынг,

к.т.н., заведующий кафедрой «Автоматика» Военно-промышленный колледж, провинция Фу Тхо, Социалистическая Республика Вьетнам, МОДЕЛИРОВАНИЕ СИСТЕМ ЭЛЕКТРОСНАБЖЕНИЯ ЖЕЛЕЗНЫХ ДОРОГ С УСТАНОВКАМИ РАСПРЕДЕЛЕННОЙ ГЕНЕРАЦИИ И НАКОПИТЕЛЯМИ ЭЛЕКТРОЭНЕРГИИ

\title{
Nguyen Van Huan, Tran Duy Hung MODEL OPERATION OF POWER SUPPLY SYSTEMS OF THE RAILROADS WITH INSTALLATIONS OF THE DISTRIBUTED OSCILLATION AND STORES OF THE ELECTRIC POWER
}

\begin{abstract}
Аннотация. Концепция интеллектуальных электрических сетей предусматривает широкое применение установок распределенной генерации (РГ) с возобновляемыми источниками и накопителей электроэнергии (НЭ), в частности, реализованных на основе аккумуляторных батарей большой энергоемкости. В докладе рассмотрены вопросы, связанные с использованием НЭ и установок РГ в системах электроснабжения нетяговых потребителей железных дорог.

Ключевые слова: Возобновляемые источники энергии, накопителя электроэнергии, сетевые кластеры.

Abstract. The systems of intelligent electrical networks provide for the wide application of distributed generation (DG) installations with renewable energy sources and energy storage devices (ESD), in particular, implemented on the basis of batteries of high power consumption. The report addresses issues related to the use of energy storage devices and distributed generation installations in consumers not traction power supply systems.
\end{abstract}

Keywords: Renewable energy sources, energy storage, network cluster.

При реализации интеллектуальных электрических сетей (smart grid) [1] предусматривается масштабное применение установок распределённой генерации (РГ). Эти установки могут работать на базе возобновляемых источников энергии (ВИЭ), что требует использования накопителей энергии (НЭ). В докладе рассмотрены вопросы, связанные с использованием ВИЭ и НЭ для электроснабжения нетяговых потребителей; при этом предполагалось формирование сетевого кластера - microgrid [2], рисунке 1. Провал напряжения [3] моделировался путем отключения основного питания нетяговых потребителей в момент времени 11 с и его подключении через 1 с. Рассматривались режимы без использования и с использованием НЭ на шинах постоянного тока ВПТ. Для повышения эффрективности работы генераторов применялись автоматические регуляторы, оснащенные звеном прогнозирования [4, 5]. Результаты моделирования показали, что при отсутствии НЭ средние и максимальные величины провалов напряжений составляли, соотвественно, 42 и 57 \%. При наличии НЭ, который подключался только при исчезновении основного питания, эти показатели были равны: 14 и 15 \%. При оснащении сети постоянно подключенным накопителем провалы напряжения исчезали. Таким образом, использование 
НЭ, постоянно подключенного к шинам постоянного тока, позволяет полностью решить проблему провалов напряжения.

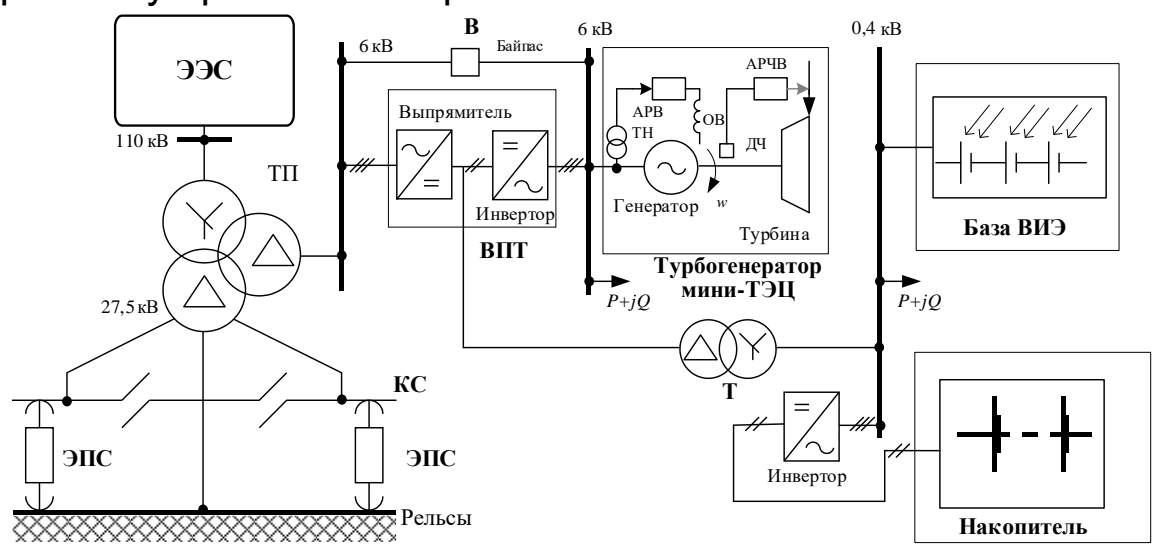

Рисунок 1. Фрагмент системы электроснабжения железной дороги:

ЭЭС - электроэнергетическая система; ЭПС - электроподвижной состав; КП - контактный провод; В - выключатель; ВПТ - вставка постоянного тока; Т трансформатор; АРВ - автоматический регулятор возбуждения; АРЧВ - автоматический регулятор частоты вращения; ДЧ - датчик частоты вращения; ОВ обмотка возбуждения; ТН - трансформатор напряжения

Результаты компьютерного моделирования позволяют сделать следующие выводы:

1. Использование постоянно подключенного НЭ на шинах постоянного тока ВПТ позволяет значительно снизить глубину провала напряжения у нетягового потребителя при временном отключении основного питания РЭС. В рассматриваемом примере снижение максимального значения глубины провала напряжения составило $57 \%$.

2. Применение автопрогностического АРЧВ позволяет существенно снизить величину перерегулирования частоты вращения ротора генератора установки РГ и время переходного процесса при временном отключении основного питания нетяговых потребителей.

\section{ЛИТЕРАТУРА}

1. Bernd M. Buchholz, Zbigniew A. Styczynski. Smart Grids - Fundamentals and Technologies in Electricity Networks // Springer-Verlag Berlin Heidelberg, 2014. $396 \mathrm{p}$.

2. Булатов Ю.Н., Крюков А.В., Чан Зюй Хынг. Сетевые кластеры в системах электроснабжения железных дорог. Иркутск: ИрГУПС, 2015. 205 с.

3. Коновалов Ю.В., Дудко А.А. Исследование свойств генерирующих электротехнических комплексов // Повышение эффрективности производства и использования энергии в условиях Сибири. Иркутск. 2014. В 2-х т. Т. 1. С. 88-92.

4. Булатов Ю.Н., Крюков А.В., Нгуен Ван Хуан. Методика настройки прогностических регуляторов установок распределенной генерации // Известия высших учебных заведений. Проблемы энергетики. № 11-12. 2016. С. 84-95. № 121. 05.12.2016.

5. Булатов Ю.Н., Крюков А.В., Нгуен Ван Хуан. Автопрогностический регулятор частоты вращения ротора генератора установки распределенной генерации // Научный вестник НГТУ. № 1(66). 2017. С. 15-25. 